\title{
Solar power moves water on rangeland
}

$\mathrm{U}$ neven range use by livestock is often the result of poor water distribution. When watering sites are sparse, livestock concentrate their grazing around the water. Both livestock performance and range condition improve if ranchers establish numerous, well-spaced water sites, each accommodating about 50 cattle or 300 sheep. But redistributing the water can be difficult because many areas are remote and have no electricity to run pumps.

As an alternative, Kern County livestock advisor Ralph Phillips and Southern California area livestock advisor Jim Sullins have investigated solar-powered pumps in cooperation with Bar Mountain Ranch in Tulare County. They compared four different types of commercial pumps with three types of water systems.

Previously, Bar Mountain Ranch had used gasoline engines and generators to pump water where electricity was not available. However, gas engines proved inconvenient and costly to operate: Someone had to drive out to each site every day and start the engines.

The initial investment in solar-powered pumps was high. The models tested ranged in cost from $\$ 1,845$ to $\$ 11,765$, excluding the cost of labor for installation. However, this initial investment became more attractive when compared to the long distances and costs of bringing in electrical grid power at $\$ 10.75$ per linear foot. "Where grid power is easily available, it's not economically viable," Phillips said. "You have to have it too long to justify the cost, as much as 20 to 30 years."

Phillips estimates cash costs for the solar units to be about $\$ 5$ per day, compared to $\$ 10.90$ per day for a gas powered system. Also, solar panel manufacturers guarantee their products will function for 20 years, which is longer than a gas engine typically lasts.

Phillips and Sullins experimented with diaphragm, centrifugal, piston, and jack pumps, which delivered from 1.5 to 7.5 gallons of water per minute (gpm), and lifted the water from 35 to 420 feet. All the pumps tested were powered by 55 -watt solar panels.

Every kind of pump worked, Phillips said, so he could not recommend one solar application over another. However, ranchers should con- sider which characteristics of the pump systems best fit their needs. All needed a DC motor or an invertor to convert the solar panels' direct current to alternating current. The number of solar panels needed was based on the gallons per day to be pumped and the lift required.

The diaphragm pump was a low flow, submersible device powered by two solar panels, moving water at $2 \mathrm{gpm}$ at 50 feet of lift or less. The 18-stage centrifugal pump with a 3-speed AC motor running on seven solar panels delivered $7.5 \mathrm{gpm}$ with a total lift of 75 feet. The piston pump required 10 solar panels to deliver about $2 \mathrm{gpm}$ with 450 feet lift. The jack pump running on five panels worked on the old windmill concept with a maximum flow rate of 6.5 gpm at 100 feet of lift. "This system is energy efficient," said Sullins, "and excellent for deep well applications and would be familiar to most ranchers, which is important for maintenance."

"Based on our experience, we prefer to use a DC motor because it starts working as soon as sunlight hits the solar panel," Phillips said, pointing out that an $\mathrm{AC}$ motor starts working gradually.

"We like to use DC submersible diaphragm pumps because when they move, the water

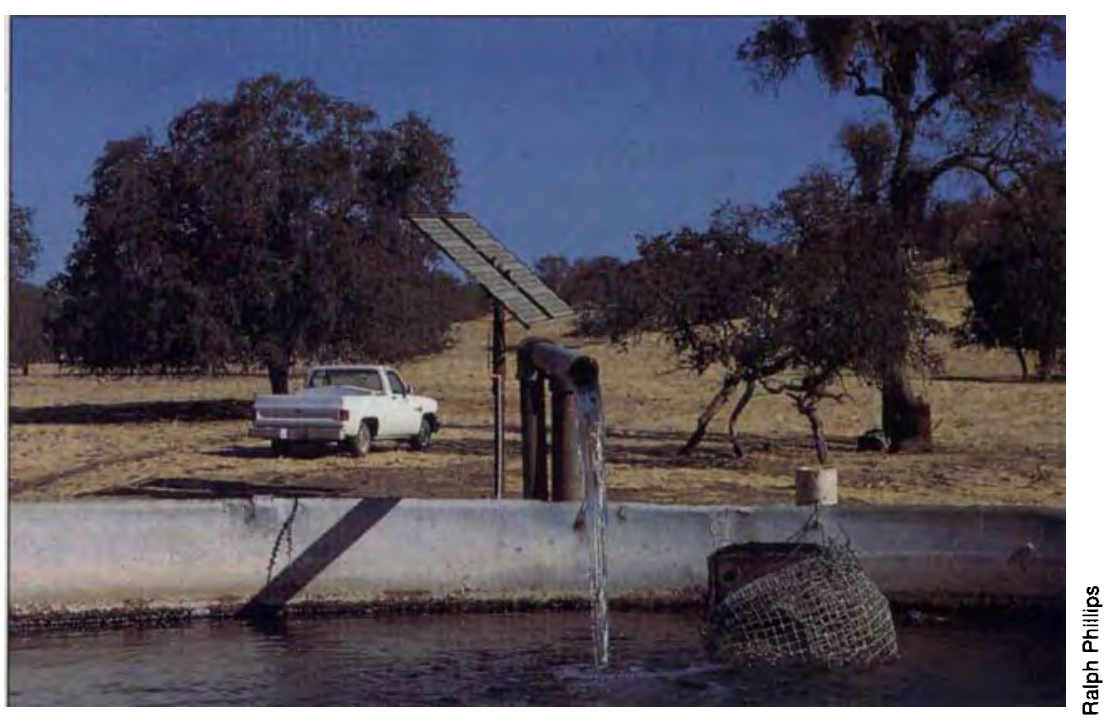

Solar power is less expensive than gas to power water pumps in remote areas where electricity is not available.

\section{'We prefer to use a DC motor because it starts working as soon as sunlight hits the solar panel'}




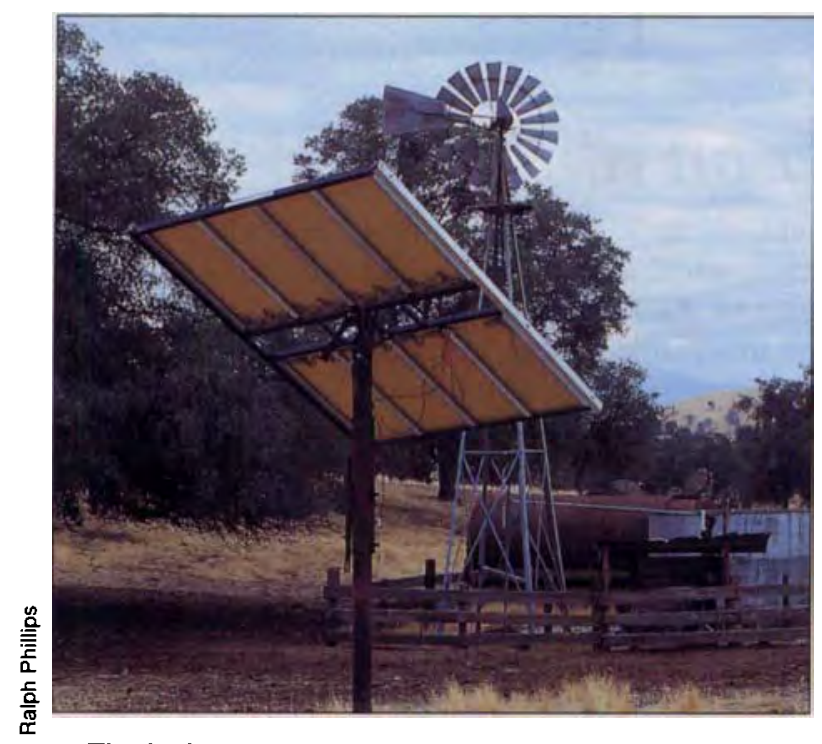

The jack pump, which works like an old windmill, is energy efficient and suitable for deep well applications.

moves. Centrifugal pumps have to build up to a certain number of rpm's before they start moving water. Early in the morning they're not very efficient."

The advisors also compared devices with solar panels that track the sun to those without trackers. "We found a $28 \%$ improvement in water movement during summer, but in Novem- ber the advantage was only 9 to $10 \%$," Phillips said.

"If you need the water supply for animals, this may not move enough water," Phillips cautioned. He prefers not to use tracking during the winter because the tracking device stops with the panels facing west, then in the morning it has to heat up before it turns toward the sun, which may not be until 10 or 11 a.m. A nontracking unit may start working at 9:30 or 10 a.m. They also learned that controllers should be placed in the shade where there is air movement to prevent overheating. When they get too hot they put out less power and may burn out.

In the next phase of their research, Phillips and Sullins, now Tulare County cooperative extension director, plan to look at combining wind and solar power into a hybrid system. "In the areas where we're using them - one is on a coastal range - we can use the breezes after the sun goes down," Phillips said. The initial investment is higher, but it can pump more water using the two types of power.

Interest in solar power is great, but adoption is slow," Phillips said. "The initial cost scares people off." - Ed.

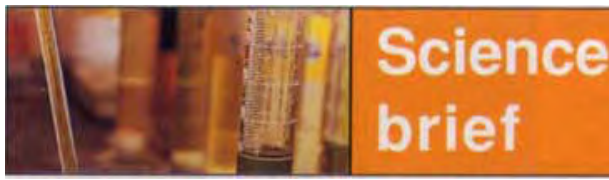

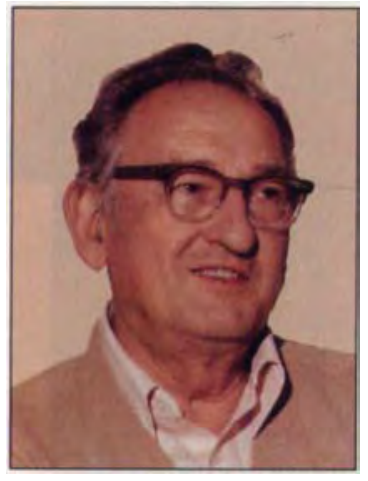

Carl B. Huffaker

\section{Huffaker wins Wolf Prize}

Carl B. Huffaker, professor emeritus of entomology at UC Berkeley and a leading expert in the biological control of weeds and insect pests, has been awarded the 1994-95 Wolf Prize, the highest honor in agriculture.

The $\$ 100,000$ prize announced by the Wolf Foundation in Tel Aviv, Israel, is to be shared by Perry L. Adkisson, former chancellor of Texas A\&M University and regents professor of entomology.

Huffaker, who retired in 1985, is known not only for his practical field work in the biological control of weeds and other pests, but for broader studies in the area of population dynamics, particularly the interactions between predator and prey.

He and Adkisson were leaders in developing the concept of integrated pest management (IPM). They documented not only that IPM works, but that it can be cost-effective. Their key contribution was leading a series of national IPM research projects, which for the first time brought together experts from many diverse fields to tackle serious major pests threatening agricultural crops. From 1972 to 1981, Huffaker was director of the IPM Project, which involved 18 universities around the country.

CAL AG on Internet: Major sections of California Agriculture are now available on the Internet Gopher system. First access the Gopher system, select "University of California Systemwide Administration" or "UC Office of the President," then "UC Systemwide Information Services," "UC Division of Agriculture and Natural Resources News and Publications" and finally "California Agriculture journal." 